Citation: Alsharhan, A. (2020). Netflix NoCensorship Policy in Subtitling Taboo Language from English into Arabic. Journal of Audiovisual Translation, 3(1), 7-28.

Editor(s): A. Matamala \& J. Pedersen Received: February 3, 2020

Accepted: October 12, 2020

Published: December 21, 2020

Copyright: (C2020 Alsharhan. This is an open access article distributed under the terms of the Creative Commons Attribution License. This allows for unrestricted use, distribution, and reproduction in any medium, provided the original author and source are credited.

\section{Netflix No-Censorship Policy in Subtitling Taboo Language from English into Arabic}

\author{
Alanoud Alsharhan ${ }^{凶}$ \\ University College London
}

\begin{abstract}
This paper aims at examining the Arabic subtitles currently used in Netflix, particularly in instances that include taboo language. Because Netflix has a no-censorship policy, identifying the different subtitling strategies that translators working for Netflix have applied, as well as determining whether they are different from those identified as the norm in subtitling taboo language into Arabic, such as omission and euphemism are important questions to be answered in this study. Subtitling strategies applied are identified and analysed while the current subtitling strategies for extralinguistic cultural references (ECRs) are used as a starting point to establish a new, modified taxonomy that represents subtitling taboo language in the two languages and cultures under analysis. The data suggest that two prominent modifications of the current subtitling strategies are needed, which are euphemism and shift in register. The audiovisual material examined in this study consists of five Netflix programs from different genres, in which taboo content and language are abundant. The subtitles of these shows are extracted in order to compile a small parallel corpus to be analysed both qualitatively and quantitively. The results indicate that a variety of subtitling strategies are used to render taboo language into Arabic on Netflix shows, which is different from previous norms that commonly used omission and other forms of euphemising taboo language. Another important result is that nearly half of the taboo language instances are still euphemised despite the no-censorship policy.
\end{abstract}

Key words: audiovisual translation (AVT), censorship, euphemism, register, subtitling strategies, taboo language.

\footnotetext{
\alanoud.alsharhan.17@ucl.ac.uk, https://orcid.org/0000-0003-4490-8005
} 


\section{Introduction}

In recent years, the internet has revolutionized the way individuals watch audiovisual material and provided many people around the world with access to content they would have never had access to before. One of the most successful companies that offers people such entertainment services via online streaming is Netflix, which has become available worldwide in over 190 countries. One of Netflix entertainment policies is to provide its users the freedom of choice when it comes to genres of audiovisual entertainment, devices used, and time and location of online streaming.

A core part of the company's view is to eliminate outdated policies and restrictions that are applied on linear television locally and globally. Accordingly, individuals who have access to Netflix content in a country such as Kuwait, where content on linear TV and cinemas is heavily scrutinized and censored, are now able to watch uncensored audiovisual material with subtitles. Subtitling uncensored audiovisual material for Arabic-speaking audiences is a new phenomenon. This new trend has attracted limited attention so far within the field of audiovisual translation (AVT).

In an attempt to address the scarcity of research on this issue, this paper ${ }^{1}$ aims to examine closely the strategies used by translators working for Netflix to translate uncensored AV material, particularly the instances that include taboo language. This is significant given the long history of euphemism, sanitization, and most often omission strategies used for translating audiovisual material into Arabic (Al-Adwan, 2015; Alkadi, 2010; Khuddro, 2000). Additionally, this examination seeks to explore whether the current taxonomies of subtitling strategies need modifications to be representative of the two languages and cultures under analysis in this study.

\section{Literature review}

\subsection{Taboo language}

Every culture has taboos, though they may differ from one culture to another. Taboo is defined as "a social or religious custom prohibiting or restricting a particular practice or forbidding association with a particular person, place, or thing" (Knowles, 2006). Taboos, however, are not exclusive to behaviors, people, places, and things; a major element of taboo is language. The language used to discuss taboos is taboo language, which is the main area of investigation of the present research study.

The concept of taboo language has been given many terms which include "taboo words" (Jay, 2009, p. 153), "linguistic taboos" (Foote \& Woodward, 1973, p. 264), "Bad Language Words (BLW)" (McEnery, 2006, p. 30), "bad language" (Andersson \& Trudgill, 1990), and a number of other names.

\footnotetext{
${ }^{1}$ This paper is part of a larger PhD thesis that started in 2017 and will be completed by the end of the year 2020.
} 
In order to understand the common denominator between these terms, it is essential to identify the characteristics that make up the concept of taboo language. Basically, the question of why certain words or phrases are considered taboo should be answered. Terminology Studies is a relevant field that could aid in tackling this question, particularly the idea of "concepts" and "concept systems," which are mental representations of objects or anything that can be conceptualized within a specialized context or field (Dubuc, 1997). Each concept has several essential characteristics that distinguish it from other concepts in the brain.

To establish this concept system, the concept of taboo language should be examined first to determine what characteristics a word or a phrase should have in order to be considered taboo language. From the previous discussion of taboo some characteristics include (a) prohibited or forbidden, (b) related to social or religious customs or aversions, (c) considered as taboo at various levels of associations, (d) considered offensive, (e) differing from one culture to another, and (f) could raise emotional ambivalence. Additionally, Jay (2009) points out other characteristics that should be added to the concept of taboo language, including the idea that it could be restricted by both authoritative institutions and individuals, as well as the assumption that some harm will occur if taboo language is used. Therefore, after consulting the literature (Allan, 2018; Allan \& Burridge, 2006; Andersson \& Trudgill, 1990; Hughes, 1998, 2015; Jay, 1992, 2000, 2009; Ljung, 2011) to determine what would be considered part of the concept system of taboo language, we would like to propose a concept map of taboo language as presented in Figure 1.

Figure 1.

Concept System of Taboo Language

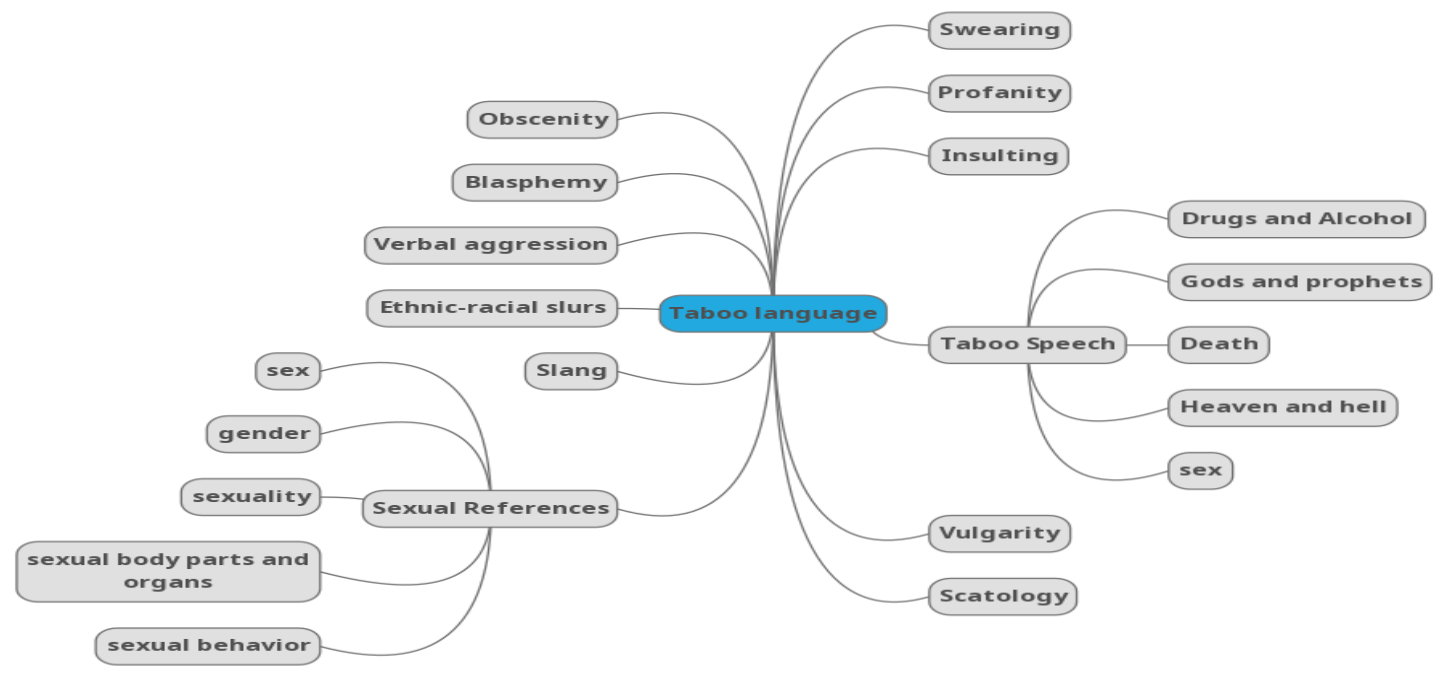




\subsection{Audiovisual translation and subtitling strategies}

In Jay's book Why We Curse (2000), he states that there are many underlying factors that explain why people use taboo language, which he classifies into three main categories: neurological, psychological, and socio-cultural. Additionally, he argues that the use of taboo language is "never chaotic, meaningless, or random behaviour, but rather purposeful and rule-governed" (Jay, 2000, p. 22). Therefore, because language used in the media is more often than not intended to resemble normal, daily conversations (Forchini, 2012), one could argue that taboo language use in the media is also meaningful and serves particular purposes and functions.

Taboo language is a complicated topic, yet an integral part of one's identity, society, and language. This subject only becomes more complicated when it comes to translating taboo language and DíazCintas expresses this well when he says that translating taboo language is "one of the most delicate issues" (2001, p. 51). While translating taboo language in audiovisual material, other factors come into play, including but not limited to the transfer from one mode to another, one language to another, and one culture to another.

Díaz-Cintas (2001) conducted an analysis on the Spanish film The Flower of My Secret, where he examined sexual references in the film subtitled from Spanish into English with the hypothesis that the only reason for deletion and naturalization of sexual references and taboo expressions would be due to time and space constraints. However, this was not his conclusion; in fact, his results were inconclusive due to inconsistencies in the strategies applied by the subtitlers. He argues (2001) that where euphemism and deletion were applied, some essential details of the characters were lost, indicating that the target audience did not necessarily experience the movie as intended. Another study looked at offensive and taboo language in the film Pulp Fiction subtitled into Spanish, and similarly the researcher concluded that $49.1 \%$ of the instances were ignored in the subtitles and only $21.3 \%$ of those could be justified by time and space constraints (Ávila-Cabrera, 2015).

When working with taboo language, it is often considered as part of the culture and dealt with according to the social norms. This is why several studies (including but not limited to Abdelaal, 2019; Ávila-Cabrera, 2016; Ávila-Cabrera, 2015; Yuan, 2015) have adopted the subtitling strategies of cultural-bound terms put forward by Díaz-Cintas and Remael (2007) and Pedersen's (2011) extralinguistic cultural references (ECRs), as they provide a reliable starting point in creating a taxonomy of subtitling taboo language. Díaz-Cintas and Remael (2007) strategies are Loan, Calque, Explicitation, Substitution, Transposition, Lexical Recreation, Compensation, Omission, and Addition (2007, p. 202). Each strategy is briefly explained in Table 1: 
Table 1.

Summary of Díaz-Cintas and Remael's (2007) Subtitling Strategies

\begin{tabular}{|c|c|}
\hline Strategy & Explanation \\
\hline Loan & $\begin{array}{l}\text { A word or phrase in the ST [Source Text] is borrowed in } \\
\text { the TT because a translation does not exist or both } \\
\text { languages use the same word. }\end{array}$ \\
\hline Calque & $\begin{array}{l}\text { A literal translation from the ST to the TT [Target Text] } \\
\text { takes place with varied levels of idiomaticity. }\end{array}$ \\
\hline Explicitation & $\begin{array}{l}\text { This involves the use of a more general translation } \\
\text { (hypernym) or a more specific one (hyponym) to make } \\
\text { the source text more accessible. }\end{array}$ \\
\hline Substitution & $\begin{array}{l}\text { It is similar to explicitation but used when there are } \\
\text { space-time constraints. }\end{array}$ \\
\hline Transposition & $\begin{array}{l}\text { A cultural concept in the ST is substituted with a cultural } \\
\text { concept that exists in the TC [Target Culture]. }\end{array}$ \\
\hline Lexical recreation & $\begin{array}{c}\text { The creation of new words or neologism in the TT when } \\
\text { a neologism is used in the ST. }\end{array}$ \\
\hline Compensation & $\begin{array}{l}\text { A faithful translation is not possible in one place but } \\
\text { could be compensated for in another location. }\end{array}$ \\
\hline Omission & It is the deletion of a translation problem. \\
\hline Addition & $\begin{array}{l}\text { It is adding information to solve any comprehension } \\
\text { problems. }\end{array}$ \\
\hline
\end{tabular}

Source: Díaz-Cintas \& Remael (2007).

Furthermore, Pedersen (2011) presents an overview of translation strategies in the literature of audiovisual translation, and based on this overview he argues that in order to create a valid taxonomy of subtitling strategies that serves the objectives of any particular translation study, there must be a baseline of strategies, which can then be generalised or specified according to the objectives of each study. This baseline is made up of six strategies: Retention, Specification, Direct Translation, Generalisation, Substitution, and Omission. Additionally, when he is particularly referring to subtitling strategies that deal with ECRs, he adds a seventh strategy, which is called Official Equivalent (Pedersen, 2011). Each strategy is briefly explained in Table 2 below: 
Table 2.

Summary of Pedersen's ECR's Subtitling Strategies

Strategy
$\begin{gathered}\text { Retention } \\ \text { Specification } \\ \text { The TT translation includes more information making it } \\ \text { more specific than the ST word or phrase. }\end{gathered}$
$\begin{gathered}\text { Translation is completed by keeping all features of the ST } \\ \text { but changing the language. }\end{gathered}$
Generalisation
The TT uses a more general term or phrase.
Omission
The ECR in the ST is substituted with an ECR that is more
common in the SC [Source Culture] or a similar one in TC.
The ECR is deleted in TT.
Official equivalent
The TT is a common translation or is enforced by an
administrative authority.

Source: Pedersen (2011).

As mentioned earlier, Netflix has a no-censorship policy, which they outline in several of their global policy statements, and they clearly state in their Quality Assurance manual in which they consider any form of censorship, including subtitles, an error that must be resolved. They state that the solution to such error is "replacing any truncated or replaced obscenities with complete words, then redeliver a new asset that does not contain any censored text" (Netflix, 2019). Therefore, by mainly adopting the taxonomy of subtitling strategies put forward by Pedersen (2011), this research paper aims at answering the following questions:

1. What modifications of Pedersen's (2011) taxonomy of ECRs' subtitling strategies may be needed for it to be representative of translating taboo language from English into Arabic?

2. What are the subtitling strategies applied by the Arabic subtitlers to translate taboo language when they abide by Netflix no-censorship enforced policy?

To answer the research questions of this paper, the methodology will be discussed in the following section. 


\section{Methodology}

This paper follows an empirical research approach ${ }^{2}$ described by Williams and Chesterman (2002) as seeking "new data, new information derived from the observation of data and from experimental work; it seeks evidence which supports or disconfirms hypotheses, or generates new ones" (p. 58). While methodology describes the overall approach of research, methods refer to the particular research techniques followed to elicit and analyse data (Saldanha \& O'Brien, 2013). In order to sufficiently answer the research questions, a corpus-based method is adopted. A corpus is "a large collection of computer-held texts, using powerful processing software" (Pérez-González, 2014, p. 165), and adopting a corpus-based method has been a common practice in conducting AVT research. The corpus was analysed both qualitatively and quantitively.

\subsection{Methods}

For this study, a parallel corpus was compiled using the English ST and the Arabic subtitles of the first five episodes of the first seasons of five Netflix original shows: Orange is the New Black, You Me Her, The Good Place, Grace and Frankie, and Disjointed. These shows were chosen because of how they are rated on Netflix given their content and the issue they raise. The shows are aimed at either teens or adults, meaning that they contain adult content and target adult audience members. Additionally, it was established as part of a pilot study that there is an abundance of taboo language in each of these shows.

The English and Arabic subtitles were extracted following freely available instructions on the Github website after an online search of how to extract Netflix subtitles. The process involved using the web browser Google Chrome, activating Netflix subtitles feature, copying and pasting online demands, and using Python and Subtitle Edit to convert the extracted English and Arabic subtitles into SRT files. All files were compiled into a parallel corpus using MemoQ, where the texts were aligned. Taboo language instances were then extracted manually for several reasons. Primarily, this decision was based on the type of taboo language instances that this study seeks to investigate. The goal is not to look for specific swearwords, such as four-letter words, but for all varieties of taboo language. Therefore, an automated word-search is not feasible. Additionally, in some instances, the taboo language is not explicit in the ST but is subtitled more explicitly in the TT. In other cases, the ST contains figurative language where the intended meaning is considered taboo. Therefore, in order not to miss any taboo language instances, manual extraction offered the best results. Then, a taboo language card was created for each instance such as the one presented in Figure 2 below. A total of 868 English-Arabic instances were extracted and analysed.

\footnotetext{
${ }^{2}$ An experimental component is included in the larger PhD study and follows Chesterman's (2000) causal model.
} 
Figure 2.

Example of Taboo Language Card

\begin{tabular}{|c|c|c|c|c|}
\hline Source Text & Target Text & Back Translation & $\begin{array}{l}\text { Taboo Lang } \\
\text { Type }\end{array}$ & $\begin{array}{l}\text { Subtitling } \\
\text { Strategy }\end{array}$ \\
\hline $\begin{array}{l}\text { I look forward to } \\
\text { helping you } \\
\text { meet and } \\
\text { exceed your } \\
\text { marijuana goals. }\end{array}$ & 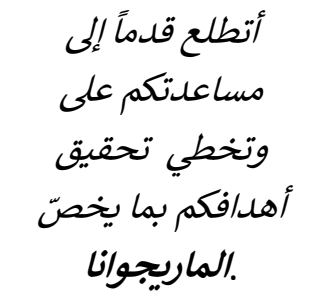 & $\begin{array}{l}\text { I look forward to } \\
\text { helping you } \\
\text { meet and exceed } \\
\text { your marijuana } \\
\text { goals. }\end{array}$ & $\begin{array}{l}\text { Drugs \& } \\
\text { Alcohol }\end{array}$ & RET \\
\hline Source & Disjointed - S1 & 39 & & \\
\hline
\end{tabular}

\subsection{Corpus Analysis and Discussion}

\subsubsection{Qualitative Analysis and Discussion}

Before analysing the taboo language instances, Pedersen's (2011) suggestion of starting with the six baseline strategies was followed. Thus, the initial list included Retention, Specification, Direct Translation, Generalisation, Substitution, and Omission. However, it quickly became apparent that when working with subtitling taboo language in this language pair and under Netflix no-censorship policy, some modifications were needed. The six strategies were not enough to represent how the subtitlers rendered taboo language instances in the data. Following Pedersen's (2011) advice, the list was expanded to serve the objective of this study. Figure 3 is the modified list of subtitling strategies that was used in analysing and discussing the data. As can be noted in Figure 3, Paraphrase and Standardisation were added as baseline strategies, and not all of Pedersen's sub-strategies were adopted because of the type of ECRs dealt with in this study. Another change in this modified list is the addition of euphemism and shift in register as features occurring with the subtitling strategies in some cases. 
Figure 3.

Modified List of the Strategies Applied for Subtitling Taboo Language from English to Arabic on Netflix

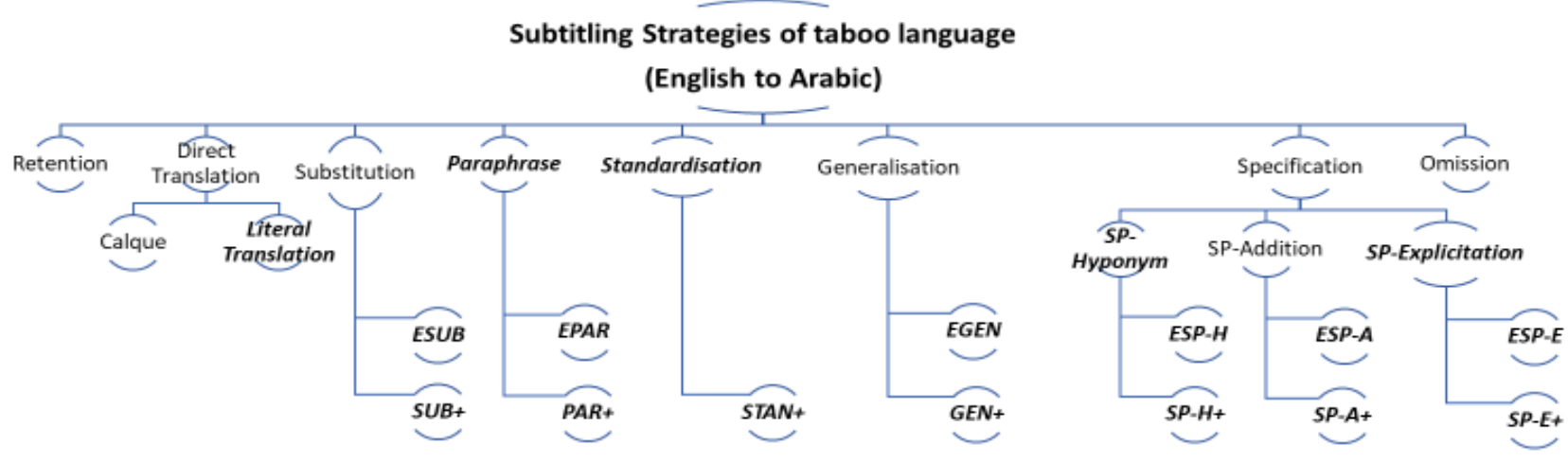

The (E) before the strategy is short for 'Euphemized'

The (+) symbol indicates a shift in register

The following is a more detailed description to illustrate how and why each taboo expression was categorised under each subtitling strategy during the data analysis phase of this study along with some examples to justify such decisions.

\section{A. Retention (RET)}

Retention is a well-established subtitling strategy in rendering ECRs and Pedersen (2011) explains it as preserving the foreign element in the $\mathrm{TT}$. He notes that Retention could also be applied by slightly adjusting the TT as in different spelling for instance (Pedersen, 2011). This idea enables the inclusion of transliterated instances where the taboo instance remains in the TT but uses Arabic alphabet. In some cases, Retention may presumably cause difficulties in understanding the text for the target audience if they are not familiar with the source language. The following two examples show the difference between a presumably successful application of retention and one that is potentially problematic.

(1) RET - Grace and Frankie S1 E1 (00:01:38)

English subtitle

You do know that vodka is made from potatoes.

Alcohol has its own rules.

Arabic subtitle

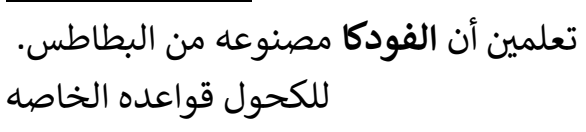

Back translation

You do know that vodka is made from potatoes. 
Alcohol has its own rules.

(2) RET - Disjointed S1 E2 (00:03:51)

English subtitle

And I would refer you to 2005's Los Angeles County v. Hector's Dildos. That was where three men were caught in a parking lot repeatedly

Arabic subtitle

وسأذكر لك القضية بين مقاطعة "لوس أنجلوس" و "هيكتورز ديلدوز" سنة 2005 حيث كان هناك ثلاثة رجال ضبطوا في موقف سيارات مراراً وتكرارً

Back translation

I would mention to you the case between Los Angeles county and Hector's Dildos in 2005, where three men were caught in a parking lot repeatedly

In both examples, the subtitler applied Retention as a strategy; while "vodka" is a common word in Arabic where the majority of people would understand that it is a type of an alcoholic drink, "dildos" is not. Since it is a name of a store, opting for Retention could be justified. However, the type of products sold in this store, which is indicated in the name, is essential for the target audience to understand the humour in this interaction.

\section{B. Direct Translation}

There appears to be some terminological variations when it comes to direct translation. For instance, Vinay and Dalbernet (2000), followed by researchers such as Ávila-Cabrera (2016, 2015), consider calque to be loan translation, whereas literal translation (LT) is a word for word translation. However, Díaz-Cintas and Remael use the terms calque and literal translation as synonyms for one another. They point out that there are levels of idiomaticity in Literal Translation, which means some literal translations are more idiomatic than others. Pedersen (2011) uses calque and shifted-direct translation as subcategories of direct translation, which is the term he uses for literal translation. He describes calque as "the result of a stringent literal translation that may appear exotic to TT audience" (Pedersen, 2011, p. 84). Therefore, to highlight the difference between less idiomatic or exotic literal translation and successful literal translation, calque and Literal translation are used as sub-strategies of direct translation. The following is an example of LT:

(3) LT-You. Me. Her. S1 E5 (00:06:49)

English subtitle

Well, why don't I vaccinate your ass with my shoe?

Arabic subtitle

حقاً؟ لم لا أطعم مؤخرتك بحذائي؟

Back translation

Really? Why don't I vaccinate your ass with my shoe? 
Calque was not a very prevalent strategy in the data, which could indicate that the translators were opting for strategies that would result in a more natural rendering. However, there were some instances that should be categorized as calque and the following is one example:

(4) CAL - Grace and Frankie S1 E4 (00:02:50)

\section{English subtitle}

we're going to be going to Robert and Sol's coming out party.

Arabic subtitle

بل سنذهب إلى حفل خروج "روبرت" و"سول".

Back translation

we're going to be going to Robert and Sol's coming out party.

This translation is considered less idiomatic in Arabic because the concept of "coming out" to other people about one's sexual orientation is not common in the culture, let alone having a "coming out party." Therefore, the Arabic word خروج basically means coming out from or exiting a physical location, which does not refer to publicly announcing one's sexual orientation.

\section{Substitution (SUB)}

In translation of ECRs, Pedersen (2011) describes substitution as a method of replacing a ST ECR with a more common one in the SC or with a similar one in the TC. He divides this category into cultural substitution, where a ECR in the ST is replaced by a more common one in the SC or by another ECR in the TC, whereas situational substitution involves completely removing a SC ECR and replacing it by something different that fits in the situation (Pedersen, 2011). Díaz-Cintas and Remael's (2007) description of substitution indicates that it is mainly used for time and space constraints. Both definitions of substitution are limiting when it comes to taboo expressions in the language pair under analysis. For example, examining the four-letter swearwords such as "fuck" and "shit," the translators often replace them with a similar swearword such as "damn," which is common in the SC and arguably more common in the TC as well. Both swearwords have equivalents in the TL, but they are not commonly used as swearwords in Modern Standard Arabic (MSA).

(5) SUB - Grace and Frankie S1 E4 (00:13:28)

English subtitle

I cannot sleep in that big fucking bed without him.

Arabic subtitle

لا يمكنني النوم في هذا السرير الكبير اللعين دونه

Back translation

I cannot sleep in that big damn bed without him. 


\section{Paraphrase (PAR)}

Paraphrase is a strategy discussed by Pedersen but as a subcategory of Generalisation, and it is used when the ECR is reduced to its sense by using a generalized paraphrase (2011). He notes that this strategy is applied "for solving ECR crisis points" (Pedersen, 2011, p. 88), which is a solution Baker (2011) also discusses to solve general translation problems rather than those limited to ECRs. She states that when some lexical items are not lexicalized or when idioms do not have an equivalent in the TL, translators commonly use paraphrase to solve such issues (Baker, 2011). Both researchers provided valuable information to refer to while analyzing the data in this study, which resulted in including this strategy as an independent one for it is frequently applied by translators. However, Paraphrase is not always a type of Generalisation, and more importantly, it is mainly used when the ST includes some form of figurative language such as metaphors or idioms as in Example 6, where the meaning is to have a baby by an interracial couple rather than to literally have a baby made from butterscotch.

(6) PAR - Disjointed S1 E2 (00:01:06)

English subtitle

Yeah, but I'm not trying to make butterscotch babies with this one.

Arabic subtitle

لكنني لا أحاول ممارسة الجنس مع هذا الرجل

Back translation

But I'm not trying to have sex with this man.

\section{E. Standardisation (STAN)}

Standardisation is another strategy that is added to this modified taxonomy of subtitling taboo language from English into Arabic. At first glance, it might seem slightly counterintuitive given the fact that the target text is Modern Standard Arabic, where the subtitles are inevitably standardised, but it is nonetheless a needed strategy for a reason. Standardisation is replacing informal, casual, and mostly dialectal taboo words with the standardised form. While the referent or the concept remains the same in both the ST and TT, there is a degree of reduced vulgarity in rendering taboo words in their standardised version that would not be accounted for if such instances are labelled Direct Translation. Even though the number of these standardised taboo expressions in the data is not huge, one intends for this taxonomy of taboo language to be recycled and used again in future studies, hence including it is essential. Example (7) demonstrates how this strategy was applied in the data. 
(7) STAN - OITNB S1 E5 (00:31:17)

\section{English subtitle}

So I'm sitting there, barbecue sauce on my titties, and I'm like, "What the fuck?"

Arabic subtitle

كنت جالسة هناك، وكانت هناك صلصة شواء على ثديي وكنت أقول لنفسي،"ماذا حدث؟

Back translation

So I'm sitting there, there was barbecue sauce on my breast, and I'm like, "What happened?"

\section{F. Generalisation (GEN)}

Pedersen (2011) describes Ggeneralisation as the process of replacing a specific word or phrase with another that is more general by using a superordinate term or paraphrase. However, since Paraphrase is used in this modified taxonomy as a separate strategy in which the presence of figurative language in the ST is essential, Generalisation here is used when the ST does not use figurative language and the subtitles in the TT are more general than the taboo language in the ST such as in Example (8).

(8) GEN - Disjointed S1 E2 (00:07:06)

English subtitle

It's my favorite indica. Very relaxing.

Arabic subtitle

إنها حشيشتي المفضلة وهي مريحة جداً

Back translation

It's my favorite hashish and it's very relaxing.

\section{G. Specification (SP)}

Díaz-Cintas and Remael (2007) combine Specification with Generalisation and call it Explicitation, whereas Pedersen (2011) uses this label for strategies in which the ECR is retained, but more information is added to make the term more specific as in spelling out an acronym. For this study, the name Specification is chosen for the baseline strategy in order to show contrast between Generalisation and Specification, but Explicitation (SP-E) is also used as a subcategory of Specification along with two others: Hyponym (SP-H) and Addition (SP-A). A Hyponym Specification is using a more specific word or term, or a word that is a type of the original word. This strategy also includes cases of synecdoche, where there is part-for-whole relationship such as in Example (9), where the word "butt" generally used as short for "buttock" was replaced with "anus" which is one part of this larger physical area. Addition is preserving the taboo instance with Retention or Direct Translation and adding more information to make the term more specific as in Example (10) where the word "sex" was added. One aspect of Explicitation would be what Pedersen considers Completion as in spelling out acronyms or using full names instead of shorter forms, but the data revealed another role of 
Explicitation. This role entails replacing a slang or made-up words in the ST with the intended meaning in the TT as in Example (11).

(9) SP-H - OITNB S1 E3 (00:17:48)

English subtitle

She probably got a voodoo spell stopping up her butt.

Arabic subtitle

الأرجح أن هناك تعويذة ودونية تسد شرجها

Back translation

She probably got a voodoo spell blocking her anus.

SP-A - Y.M.H S1 E4 (00:13:25)

\section{English subtitle}

So, you think Ava and Lori assume a young woman visiting our house automatically means we're having a three-way?

Arabic subtitle

إذاً أنت تعتقد أن "أفا" و"لوري" تفترضان أن زيارة شابة لمنزلنا تعني تلقائياً أننا نمارس جنساً ثلاثياً؟

Back translation

So, you think Ava and Lori assume a young woman visiting our house automatically means we're having three-way sex?

$$
\text { SP-E - OITNB S1 E3 (00:09:48) }
$$

English subtitle

Don't tell me you'd hit that?

Arabic subtitle

لا تقل لي إنك مستعد لمضاجعتها

Back translation

Don't tell me you're willing to fuck her?

\section{H. Omission (OMS)}

Omission is the last subtitling strategy in which the taboo instance in the ST is deleted in the TT. This strategy is commonly used as a solution for time and space constraints, but this is not always the case. Some translators opt for this strategy for various reasons, including censorship, problematic translations, lack of knowledge, or as Pedersen puts it "out of laziness" $(2011$, p. 96). In other cases, the translator may have opted for Omission because the ST is too common or well-known in the TT, so a translation would not be needed. The main point is that Omission is not always used to solve time and space constraints, but it could be a conscious decision made by the translator. It is sometimes difficult to pinpoint the justification behind Omission when it is apparent that there were no time and space constraints. The following is an example of Omission where time and space constraints were clearly not the reason. 
(12)

$$
\text { OMS - OITNB S1 E2 (00:09:18) }
$$

English subtitle

Check this shit out.

Arabic subtitle

انظري إلى هذا

Back translation

Look at this.

\section{Euphemism and Shift in Register as Added Features to the Subtitling Strategies}

The data suggest that two additional modifications to the current taxonomies of subtitling strategies are needed, which are euphemism and shift in register. Previous studies dealing with subtitling from English to Arabic (such as Al-Adwan, 2015; Alkadi, 2010; Khuddro, 2000) have concluded that euphemism is a common way of producing Arabic subtitles. This is understandable given the conservatism of the Arab culture and the enforced censorship policies in most Arab countries. One definition that sufficiently explains euphemism in an AVT context is put forward by Allan and Burridge; "a euphemism is used as an alternative to a dispreferred expression, in order to avoid possible loss of face: either one's own face or, through giving offence, that of the audience, or of some third party" (Allan \& Burridge, 1991, p. 11). In AVT, one type of such dispreferred language is taboo language presented in AV material, and the translators tend to apply euphemized subtitling strategies for Arab audiences.

Al-Adwan (2015) proposed a model of euphemization for subtitling into Arabic, and it includes seven strategies that fall under euphemism. Those strategies are (1) widening, (2) implication, (3) metonym, (4) demetaphorisation, (5) borrowing, (6) semantic misrepresentation, and (7) omission. Al-Adwan's (2015) model fundamentally assumes that all instances containing taboo language are euphemized when subtitled into Arabic, which is not always the case. Similarly, Abdelaal added two ECR subtitling strategies to his initial list, which was based on Pedersen's (2011) taxonomy of subtitling strategies; the additional strategies are "translation using euphemistic expression" (Abdelaal, 2019, p. 11) and "rendering informal language formal" (p. 19). However, one could argue that such changes do not occur independent from a subtitling strategy, but as additional features to a strategy, which is how the current study dealt with them. Indeed, such an approach seems to do more justice to the complexity of both taboo language as a phenomenon as well as pertinent translation decisions. In Example (12), the word "penis" was subtitled as "عضو ذكري" or "male organ," in which the subtitler clearly used a superordinate term and a euphemized one at the same time. Thus, this is represented by adding I before the subtitling strategy to indicate that it is a euphemized generalisation (EGEN).

$$
\text { EGEN - OITNB S1 E1 (00:18:50) }
$$

English subtitle

Look! I found a rock that looks like a penis.

$\underline{\text { Arabic subtitle }}$ 
انظر، وجدت صخرة شكلها كعضو ذكري

Back translation

Look! I found a rock that looks like a male organ.

The other important feature that is added to the subtitling strategies is a shift in register. Register is a sociolinguistic concept that has been investigated by many but primarily by Halliday and Hasan (1976). Halliday and Hasan define register as "the set of meanings, the configurations of semantic patterns, that are typically drawn upon under the specified conditions, along with the words and structures that are used in realization of these meanings" (Halliday \& Hasan, 1976, p. 23). Register includes different components of meaning to be configured, and those are field, mode, and tenor. Field is defined as "the total event, in which the text is functioning, together with the purposive activity of the speaker or writer; it thus includes the subject-matter as one element in it" (Halliday \& Hasan, 1976, p. 22). Mode is defined as "the function of the text in the event, including therefore both the channel taken by the language-spoken or written, extempore or prepared-and its [genre], or rhetorical mode, as narrative, didactic, persuasive, 'phatic communion' and so on"(Halliday \& Hasan, 1976, p. 22). Tenor refers to "the type of role interaction, the set of relevant social relations, permanent and temporary, among the participants involved" (Halliday \& Hasan, 1976, p. 22).

For the translators to produce high quality translations, they should ensure that there is a match in register. Husni and Neman warn against neglecting the role of register and emphasize that it is "a crucial component in natural idiomatic speech and getting it wrong can lead to pragmatic mismatches, shifts in meaning, as well as unwanted comical effects if it doesn't fit the text type, character, and context" $(2015$, p. 57). Given the fact that the data under analysis in this study is subtitles, there is always a shift in mode from spoken to written. Additionally, because the subtitles are rendered in Modern Standard Arabic, which is considered a formal or academic language and rarely used for conversational purposes, it could be argued that escaping a shift in register is nearly impossible. However, putting those two facts aside, any additional shifts in register components are represented in the data by adding a plus symbol $(+)$ to the subtitling strategy. The plus symbol represents the presence of any shift in register, whether upward or downward. If there is no shift in register, this means the register stays the same in the subtitles. In the following example from Orange is the New Black, the strategy applied is Euphemized Substitution with a shift in register (ESUB+) because the taboo language is removed, and there is a shift in tenor given that the characters interacting are both inmates in prison, where swearing would be common.

$$
\text { ESUB+- OITNB [Orange is the New Black] S1 E4 (00:46:12) }
$$

\section{English subtitle}

All that murder talk is rumor, and if you ask me, bullshit.

Arabic subtitle

كل ما يقال عن أنها قاتلة شائعات وإن أردت أيي، فهو هراء

Back translation

All that murder talk is rumor, and if you want my opinion, it's nonsense. 


\subsubsection{Quantitative Analysis and Discussion}

The quantitative analysis in this section was completed using basic formulas in Excel. One of the major observations was that despite previous common practice, the Arabic subtitles of taboo language on Netflix were completed using all the subtitling strategies in the modified list discussed in the previous section. This indicates that lifting censorship policies allowed subtitlers to be more creative in how they rendered taboo language. Table 3 is a summary of the distribution of these subtitling strategies as found in the data.

Table 3.

Total Number of Subtitling Strategies of Taboo Language

\begin{tabular}{ccc}
\hline Subtitling Strategy & Number of Instances & Percentage \\
\hline Retention & 23 & $2.65 \%$ \\
Direct Translation & 190 & $21.89 \%$ \\
Substitution & 191 & $22 \%$ \\
Paraphrase & 113 & $13.02 \%$ \\
Standardisation & 40 & $4.61 \%$ \\
Generalisation & 103 & $11.87 \%$ \\
Specification & 125 & $14.4 \%$ \\
Omission & 83 & $9.56 \%$ \\
Total & 868 & $100 \%$ \\
\hline
\end{tabular}

Retention in this parallel corpus raised some intriguing questions because of inconsistent application. In many cases, it was used to render names of types of drugs and alcohol, such as vodka, tequila, marijuana, which could be considered an appropriate strategy as they are common in both the SC and TC. However, this was not a consistent practice as in other cases where names of types of drugs and alcohol are included, such as Valium and Cialis, other subtitling strategies were applied. Furthermore, Retention was applied in cases where it could have resulted in some comprehension problems, due to lack of familiarity of the taboo instance in the target text, such as in Example (2) discussed above.

Direct translation strategies were mainly applied to translate sexual body parts such as "ass," swearwords "bitch," and to describe sexual actions, e.g. "you can suck it out of my dick" from OITNB. In cases where the word-for-word translation is less idiomatic in the TT, the subtitling strategy applied is labelled as Calque. Direct translations do not seem to cause many problematic renderings when applied to translating taboo language into Arabic. Substitution was mainly used to substitute fourletter swearwords, mainly "fuck" and "shit" and their variants, with other swearwords more common in the TC such as "damn." 
Paraphrase is one of the added strategies to the list as mentioned previously and used in a slightly different way from Pedersen's (2011). It was mainly used when the taboo language was used figuratively in the ST, whereas the TT rendition lacked figurative language by unpacking the meaning. When it was used for swearwords like "dickheads" or "you look like an asshole" it did not cause translation problems and appeared to be a successful solution. However, in some cases where the figurative language was used for specific purposes as in for humorous effects, paraphrase led to the loss of these intended effects. One example to illustrate this idea is from OITNB where one of the main characters is served a sandwich with a used tampon because she insulted the prison's cook. This is uttered in the dialogue as "egg McTampon. Rare" referencing the fast food chain McDonalds, but the translation was too descriptive "a sandwich with a bloody tampon instead of eggs" causing the reference to be lost.

Generalisation was mainly used for slang in the ST. For example, slang for types of drugs "pot," "Indica," and "dope" are all translated as "drugs" or "marijuana." Standardisation was mainly used for informal and dialectical forms of sexual body parts, such as "boobies," "titties" being translated as "breasts," or "cock" as "penis." Specification strategies were also used for slang expressions related to drugs. For instance, words like "crack," "meth," and "stoned" in the ST were subtitled as "cocaine" and "methamphetamine" and "high" respectively in the TT. Slang words or phrases describing sexual acts as in "get a handy" and "blowjob" were specified in the subtitles resulting in "get a hand foreplay" and "suck each other's penises," which could arguably make the vulgarity in TT slightly stronger than the ST. Finally, omission was surprisingly one of the least commonly used strategies in the data. A detailed analysis of the number of characters and duration of subtitles where Omission was applied was not undertaken. Thus, this study does not offer a definitive answer as to why the subtitlers opted for Omission. However, in many such instances this was obviously not the reason because the lines were too short, which may indicate evidence of self-censorship.

The results also showed that where euphemism is possible, more than $45 \%$ of the taboo language instances were in fact euphemized despite Netflix no-censorship policy. This could be attributed to the idea of norms introduced by Toury (1980) in that Arabic subtitlers are used to euphemizing taboo language, which caused them to apply it even though they were not obligated to do so. The following table summarizes how often euphemism was added to each subtitling strategy. This excludes retention, direct translation, and omission. Euphemism could not be added to strategies where the taboo expressions are kept as is in the TT or translated word-for-word. Standardisation instances were also excluded from the quantitative analysis of euphemism because even though there is a reduced level of vulgarity in the $\mathrm{TT}$, a rendition of a taboo concept remained in the subtitles only in a milder more formal form. Note that omission could have been applied for euphemizing purposes but since a detailed analysis of reasons behind omission was not conducted, omission instances were excluded from this summary.

Based on the previous definition of euphemism, this feature is added to a subtitling strategy when the vulgarity of the taboo language is no longer present in the TT. For example, a character in OITNB 
asks "you like pussy Piper?" but the subtitle reads "you like women Piper?," this is considered a euphemized generalisation because the TT lacks any form of taboo language. "Women" is a more general term than "pussy" since the latter is a part of a woman's anatomy, but the term "women" is not considered taboo language hence it is a euphemized subtitling strategy.

Table 4.

Total Number of Euphemized Subtitling Strategies

\begin{tabular}{cccc}
\hline Subtitling Strategy & Number of Instances & Number of Euphemisms & Percentage \\
\hline Substitution & 191 & 119 & $22.37 \%$ \\
Paraphrase & 113 & 66 & $12.41 \%$ \\
Generalisation & 103 & 42 & $7.89 \%$ \\
Specification & 125 & 15 & $2.82 \%$ \\
Total & 532 & 242 & $45.49 \%$ \\
\hline
\end{tabular}

Moreover, it was noted in the results that whenever euphemism was added to the subtitling strategies, it led to a shift in register, but the latter also occurred independent from euphemism. With Standardisation, escaping a shift in register was impossible, meaning all such instances occurred with a shift in register. Taking the same example mentioned in the previous paragraph, the character continues "you like pussy Piper? Or you prefer pipe as your name suggests?"; the first taboo instance was subtitled with a euphemized generalisation, whereas the second as a euphemized paraphrase, resulting in the following back translation "you like women Piper? Or you prefer men as your name suggests." In both cases there was a shift of register EGEN+ [Euphemized Generalisation] and EPAR+ [Euphemized Paraphrase] mainly due to the shift in tenor as the characters in this dialogue are inmates having a conversation about sexual orientation preferences. One could argue that there is a shift in field as well because the topic is no longer about sexual organs but about gender. Additionally, the metaphor in the second taboo language instance is completely lost in the Arabic subtitles and could lead to some translation problems and confusion since the Arabic word for "men" does not share any metaphorical reference with the character's name. The following table summarizes the total number of subtitling strategies with a shift in register. 
Table 5.

Total Number of Subtitling Strategies with a Shift in Register

\begin{tabular}{cccc}
\hline Subtitling strategy & Number of Instances & $\begin{array}{c}\text { Number of Shifts } \\
\text { in Register }\end{array}$ & Percentage \\
\hline Substitution & 191 & 142 & $24.83 \%$ \\
Paraphrase & 113 & 107 & $18.71 \%$ \\
Standardisation & 40 & 40 & $7 \%$ \\
Generalisation & 103 & 69 & $12.06 \%$ \\
Specification & 125 & 51 & $8.92 \%$ \\
Total & 572 & 409 & $71.5 \%$ \\
\hline
\end{tabular}

All in all, the results indicated that subtitlers working for Netflix used a variety of subtitling strategies to render taboo language instances in the $T$, which could lead to a more faithful rendition of the ST and provide the audience members with a more authentic experience while watching these programs. Moreover, the results showed that a large percentage of the taboo language instances were still euphemized, while even a larger percentage indicated a shift in register, which could cause a shift in overall meanings of such instances. Thus, to determine how successful these subtitling strategies are, the second part of this study will consider the multimodal nature of AVT as well as the audience reception of the subtitles.

\section{Conclusion}

This paper aimed to answer two main questions. The first was to determine whether any modifications of the taxonomy of subtitling strategies were needed to account for translating taboo language from English into Arabic. The second question was to identify the subtitling strategies used by subtitlers working for Netflix to translate taboo language in this language pair when they abide by Netflix no-censorship policy. The data analysis was conducted both qualitatively and quantitatively. This enabled the researcher to modify the current taxonomy of subtitling strategies put forward by Pedersen's (2011) in order to represent taboo language instances subtitled into Arabic. The modifications that were needed to account for all taboo language instances included adding paraphrase and standardisation as subtitling strategies as well as allowing for additional changes due to euphemism and shift in register. The results indicated that a variety of subtitling strategies were applied by the subtitlers. Furthermore, euphemisms and shift in register were still prevalent in the subtitles. Further research that concerns AVT's multimodality and audience reception ${ }^{3}$ is needed to accurately evaluate how successful these strategies are.

\footnotetext{
${ }^{3}$ The second part of the $\mathrm{PhD}$ thesis includes an experiment involving audience members to address this research niche.
} 


\section{References}

Abdelaal, N. M. (2019). Subtitling of culture-bound terms: Strategies and quality assessment. Heliyon, 5(4), doi:10.1016/j.heliyon.2019.e01411

Al-Adwan, A. S. (2015). Towards a model of euphemisation in Arabic subtitling. Arab World English Journal, 4, 6-21.

Alkadi, T. (2010). Issues in the subtitling and dubbing of English-language films into Arabic: problems and solutions. (PhD), University of Durham, UK.

Allan, K. (2018). The Oxford handbook of taboo words and language. New York: Oxford University Press.

Allan, K., \& Burridge, K. (1991). Euphemism \& dysphemism: language used as shield and weapon. New York: Oxford University Press.

Allan, K., \& Burridge, K. (2006). Forbidden words: Taboo and the censoring of language. New York: Cambridge University Press.

Andersson, L., \& Trudgill, P. (1990). Bad language. Oxford: Basil Blackwell by arrangement with Penguin Books.

Ávila-Cabrera, J. J. (2015). Subtitling Tarantino's offensive and taboo dialogue exchanges into European Spanish: the case of Pulp Fiction. Revista de Lingüística y Lenguas Aplicadas, 10(1). 1-11. doi:10.4995/rlyla.2015.3419

Ávila-Cabrera, J. (2016). The treatment of offensive and taboo terms in the subtitling of Reservoir Dogs into Spanish. TRANS. Revista de Traductología, (20), 25-40.

Baker, M. (2011). In other words: A coursebook on translation (2nd ed.). London, Abingdon [England], New York: Routledge.

Chesterman, A. (2000). A causal model for translation studies. In Y. Gambier (Ed.), Reflections on translation theory: Selected papers 1993-2014 (pp. 123-136). Amsterdam, Philadelphia: John Benjamins.

Díaz-Cintas, J. (2001). Sex (sub)titles and videotapes. In L. Lorenzo García \& A. M. Pereira Rodríguez (Eds.), El subtitulado: (inglés/español/galego) (pp. 47-67). Vigo: Universidade de Vigo.

Díaz-Cintas, J., \& Remael, A. (2007). Audiovisual translation: subtitling. Manchester: St. Jerome.

Dubuc, R. (1997). Terminology: A practical approach. Canada: Linguatech.

Netflix, (2019). Extraneous content - censorship. Retrieved from https://partnerhelp.netflixstudios.com/hc/en-us/articles/221292467-Extraneous-ContentCensorship-Text-

Foote, R., \& Woodward, J. (1973). A preliminary investigation of obscene language. The Journal of Psychology, 83(2), 263-275. https://doi:10.1080/00223980.1973.9915614

Forchini, P. (2012). Movie language revisited. Evidence from multi-dimensional analysis and corpora. Switzerland: Peter Lang.

Halliday, M. A. K., \& Hasan, R. (1976). Cohesion in English. London: Longman.

Hughes, G. (1998). Swearing: A social history of foul language, oaths and profanity in English. London: Penguin Books.

Hughes, G. (2015). An encyclopedia of swearing: The social history of oaths, profanity, foul language, and ethnic slurs in the English-speaking world. London: Routledge.

Husni, R., \& Newman, D. L. (2015). Arabic-English-Arabic translation: Issues and strategies. London: Routledge.

Javerbaum, D., \& Lorre, C. (Writer) \& Burrows, J. (Director). (2017). Disjointed [Television series]. In Lorre, C (producer). USA: Warner Bros. 
Jay, T. (1992). Cursing in America: A psycholinguistic study of dirty language in the courts, in the movies, in the schoolyards, and on the streets. Amsterdam, Philadelphia: John Benjamins.

Jay, T. (2000). Why we curse: A neuro-psycho-social theory of speech. Philadelphia: John Benjamins.

Jay, T. (2009). The utility and ubiquity of taboo words. Perspectives on Psychological Science: $A$ Journal of the Association for Psychological Science, 4(2), 153-161. doi:10.1111/j.17456924.2009.01115.x

Kauffman, M., \& Morris, H (Writer), \& Taylor, T (Director). (2015). Grace and Frankie [Television Series]. California: Skydance Television.

Khuddro, A. (2000). Subtitling in Arabic. Turjuman: Revue de Traduction et d'Interprétation: Journal of Translation Studies, 9(1), 31-37.

Knowles, E. (2006). Taboo. In: The Oxford dictionary of phrase and fable (2 ed.): Oxford University Press. Retrieved from https://www.oxfordreference.com/view/10.1093/acref/9780198609810.001.0001/acref9780198609810-e-6931?rskey=Y6rzeV\&result=6930

Kohan, J. (Writer), \& Trim, M. (Director). (2013). Orange is the new black [Television Series]. USA: Lions Gate Entertainment.

Ljung, M. (2011). Swearing: A cross-cultural linguistic study. Houndmills, Basingstoke, Hampshire, NY: Palgrave Macmillan.

McEnery, T. (2006). Swearing in English: Bad language, purity and power from 1586 to the present. London: Routledge.

Pedersen, J. (2011). Subtitling norms for television an exploration focusing on extralinguistic cultural references. Amsterdam, Philadelphia: John Benjamins.

Pérez-González, L. (2014). Audiovisual translation: Theories, methods and issues. London, New York: Routledge.

Saldanha, G., \& O’Brien, S. (2013). Research methodologies in translation studies. Manchester: St. Jerome.

Schur, M. (Writer), \& Goddard, D. (Director). (2016). The good place [Television Series]. USA: NBC.

Shepherd, J. (Writer), \& Ganatra, N. (Director). (2016). You me her [Television Series]. Canada: Audience.

Toury, G. (1980). In search of a theory of translation. Tel Aviv: The Porter Institute of Poetics and Semiotics.

Toury, G. (1995). Descriptive translation studies and beyond. Amsterdam, Philadelphia: John Benjamins.

Vinay, J., \& Dalbernet, J. (2000). A methodology for translation. In L. Venuti (Ed.), The translation studies reader. London: Routledge.

Williams, J., \& Chesterman, A. (2002). The map: A beginner's guide to doing research in translation studies. Manchester: St. Jerome.

Yuan, L. (2015). The subtitling of sexual taboo from English to Chinese. London: ProQuest Dissertations. 